\title{
Do Physicians Understand Cancer Screening Statistics? A National Survey of Primary Care Physicians in the United States
}

Odette Wegwarth, PhD; Lisa M. Schwartz, MD, MS; Steven Woloshin, MD, MS; Wolfgang Gaissmaier, PhD; and Gerd Gigerenzer, PhD

Background: Unlike reduced mortality rates, improved survival rates and increased early detection do not prove that cancer screening tests save lives. Nevertheless, these 2 statistics are often used to promote screening.

Objective: To learn whether primary care physicians understand which statistics provide evidence about whether screening saves lives.

Design: Parallel-group, randomized trial (randomization controlled for order effect only), conducted by Internet survey. (ClinicalTrials. gov registration number: NCT00981019)

Setting: National sample of U.S. primary care physicians from a research panel maintained by Harris Interactive (79\% cooperation rate).

Participants: 297 physicians who practiced both inpatient and outpatient medicine were surveyed in 2010, and 115 physicians who practiced exclusively outpatient medicine were surveyed in 2011.

Intervention: Physicians received scenarios about the effect of 2 hypothetical screening tests: The effect was described as improved 5-year survival and increased early detection in one scenario and as decreased cancer mortality and increased incidence in the other.

Measurements: Physicians' recommendation of screening and perception of its benefit in the scenarios and general knowledge of screening statistics.
Results: Primary care physicians were more enthusiastic about the screening test supported by irrelevant evidence (5-year survival increased from $68 \%$ to $99 \%$ ) than about the test supported by relevant evidence (cancer mortality reduced from 2 to 1.6 in 1000 persons). When presented with irrelevant evidence, $69 \%$ of physicians recommended the test, compared with $23 \%$ when presented with relevant evidence $(P<0.001)$. When asked general knowledge questions about screening statistics, many physicians did not distinguish between irrelevant and relevant screening evidence; $76 \%$ versus $81 \%$, respectively, stated that each of these statistics proves that screening saves lives $(P=0.39)$. About one half $(47 \%)$ of the physicians incorrectly said that finding more cases of cancer in screened as opposed to unscreened populations "proves that screening saves lives."

Limitation: Physicians' recommendations for screening were based on hypothetical scenarios, not actual practice.

Conclusion: Most primary care physicians mistakenly interpreted improved survival and increased detection with screening as evidence that screening saves lives. Few correctly recognized that only reduced mortality in a randomized trial constitutes evidence of the benefit of screening.

Primary Funding Source: Harding Center for Risk Literacy, Max Planck Institute for Human Development.

Ann Intern Med. 2012;156:340-349.

www.annals.org

For author affiliations, see end of text.

ine a group of patients in whom cancer was diagnosed because of symptoms at age 67 years, all of whom die at age 70 years (2). Each patient survives only 3 years, so the 5 -year survival for the group is $0 \%$. Now imagine that the same group undergoes screening. Screening tests by definition lead to earlier diagnosis. Suppose that with screening, cancer is diagnosed in all patients at age 60 years, but they nevertheless die at age 70 years. In this scenario, each patient survives 10 years, so the 5-year survival for the group is $100 \%$. Yet, despite this dramatic improvement in survival (from $0 \%$ to 100\%), nothing has changed about how many people die or when.

Figure 1 further shows how overdiagnosis distorts survival statistics. Imagine a population in which cancer detected because of symptoms is diagnosed in 1000 people and that 400 are alive 5 years later, for a 5 -year survival rate of $40 \%$. Now imagine that the population had undergone screening. Screening can detect cases of cancer that are not destined to progress, a phenomenon known as overdiagnosis (3-6). Since these cases of cancer are nonprogressive, these patients will survive 5 years. The addition of the overdiagnosed cancer cases distorts the 5-year survival statistic by inflating the numerator and the denominator. Suppose 2000 cases of cancer were overdiagnosed. In this case, after 5 years, 
Do Physicians Understand Cancer Screening Statistics? ORIGINAL RESEARCH

2400 people will be alive out of the 3000 diagnosed —an $80 \%$ 5 -year survival rate. But again, despite the dramatic improvement in survival (from $40 \%$ to $80 \%$ ), nothing has changed about how many people die or when.

In contrast to survival and early detection rates for cancer, cancer mortality rates are unaffected by lead-time and overdiagnosis biases. This is because mortality statistics simply divide the number of deaths from cancer by all people in the study population. Mortality statistics are also not distorted by the timing of diagnosis because all deaths that occur in the study population over a given period of time are counted. Because lead-time and overdiagnosis biases do not affect mortality statistics, an extramural committee of the National Cancer Institute concluded that reduced mortality in a randomized trial is the only statistic that reliably proves that a screening test saves lives (7).

Misunderstanding of survival and early-stage statistics may stimulate enthusiasm about using unproven tests. We sought to learn how well U.S. primary care physicians understand common statistics used to discuss cancer screening. Our goal was to see whether physicians know which statistics constitute proof of the benefit of screening.

\section{Methods}

Researchers at the Max Planck Institute for Human Development (Berlin, Germany) the Veterans Affairs Outcomes Group (White River Junction, Vermont), and the Dartmouth Institute for Health Policy and Clinical Practice (Lebanon, New Hampshire) developed the content and design of the questionnaire. Harris Interactive (Hamburg, Germany) programmed the online version of the questionnaire. In December 2009, Harris Interactive conducted the online survey by using a national sample of U.S. primary care physicians (Figure 2). The study was approved by the institutional ethics board of the Max Planck Institute for Human Development and registered on ClinicalTrials.gov (NCT00981019).

\section{Sample Frame}

The sample frame was the Harris Interactive Physician Panel. The panel is representative of the general U.S. physician population (physician information is continuously updated and authenticated with the American Medical Association's Masterfile) and comprises about 45000 U.S. physicians across all major medical specialties who have agreed in advance to participate in online research (8).

\section{Sample Selection}

Our goal was to survey a national random sample of primary care physicians in the United States because screening tests are an important part of their usual clinical practice. We specifically targeted physicians who actively provide direct patient care in 3 specialties: family medicine, internal medicine, and general medicine. To detect differences of $20 \%$ or greater with $90 \%$ power in the proportion of respondents correctly answering questions about 5-year

\section{Context}

Because primary care physicians recommend cancer screening to patients, it is important that they be able to correctly interpret screening results.

\section{Contribution}

Primary care physicians were presented with 2 hypothetical scenarios regarding cancer screening. In one, screening improved 5-year survival and increased early detection; in the other, screening decreased cancer mortality and incidence. Most physicians incorrectly equated improved survival and early detection as evidence of lives saved by screening.

\section{Caution}

The effect of subjective factors, such as fear of malpractice, on interpretation was not studied. No information on testing harms was provided within the scenarios.

\section{Implication}

Primary care physicians may not understand how to interpret the results of cancer screening tests that they commonly order for patients.

\section{-The Editors}

survival and mortality (2-sided $\alpha$ value of 0.05 ), we calculated that a sample size of 300 physicians was needed. To allow for nonresponse and ineligibility, Harris Interactive drew a simple random sample of 778 U.S. physicians in the 3 target specialties from their Physician Panel.

\section{Survey Administration}

In December 2009, Harris Interactive e-mailed the physicians in the selected sample (Figure 2). The e-mail provided basic information about the study, the link to the survey (with a personalized password), and an offer of a $\$ 70$ honorarium upon completion of the survey. Follow-up e-mail reminders were sent to nonrespondents until the planned sample size was met (which happened 2 weeks later).

Of the 778 physicians invited, 713 responded to the survey and 65 did not. Of the 713 who responded, 94 did not work in any of the 3 target primary care specialties, 4 reported exclusively inpatient practice, and 79 logged on after the survey was closed. Of the remaining 536 potentially eligible physicians, 239 working exclusively in outpatient care were inadvertently excluded owing to a programming error; the remaining 297, who worked in both inpatient and outpatient care, completed the survey (wave 1). The 239 wrongly excluded physicians were recontacted approximately 1 year after the original survey. Our budget accommodated another 115 respondents (wave 2), enabling us to approximate the distribution in the original sample. Of the recontacted physicians, 115 completed the survey, 79 logged on to the survey after it was closed, and 45 did not respond. Thus, for both waves, a total of 412 physicians eventually completed the survey (297

6 March $2012 \mid$ Annals of Internal Medicine $\mid$ Volume 156 • Number $5 \mid \mathbf{3 4 1}$ 
ORIginal ReSEARCH Do Physicians Understand Cancer Screening Statistics?

Figure 1. Lead-time bias and overdiagnosis bias.
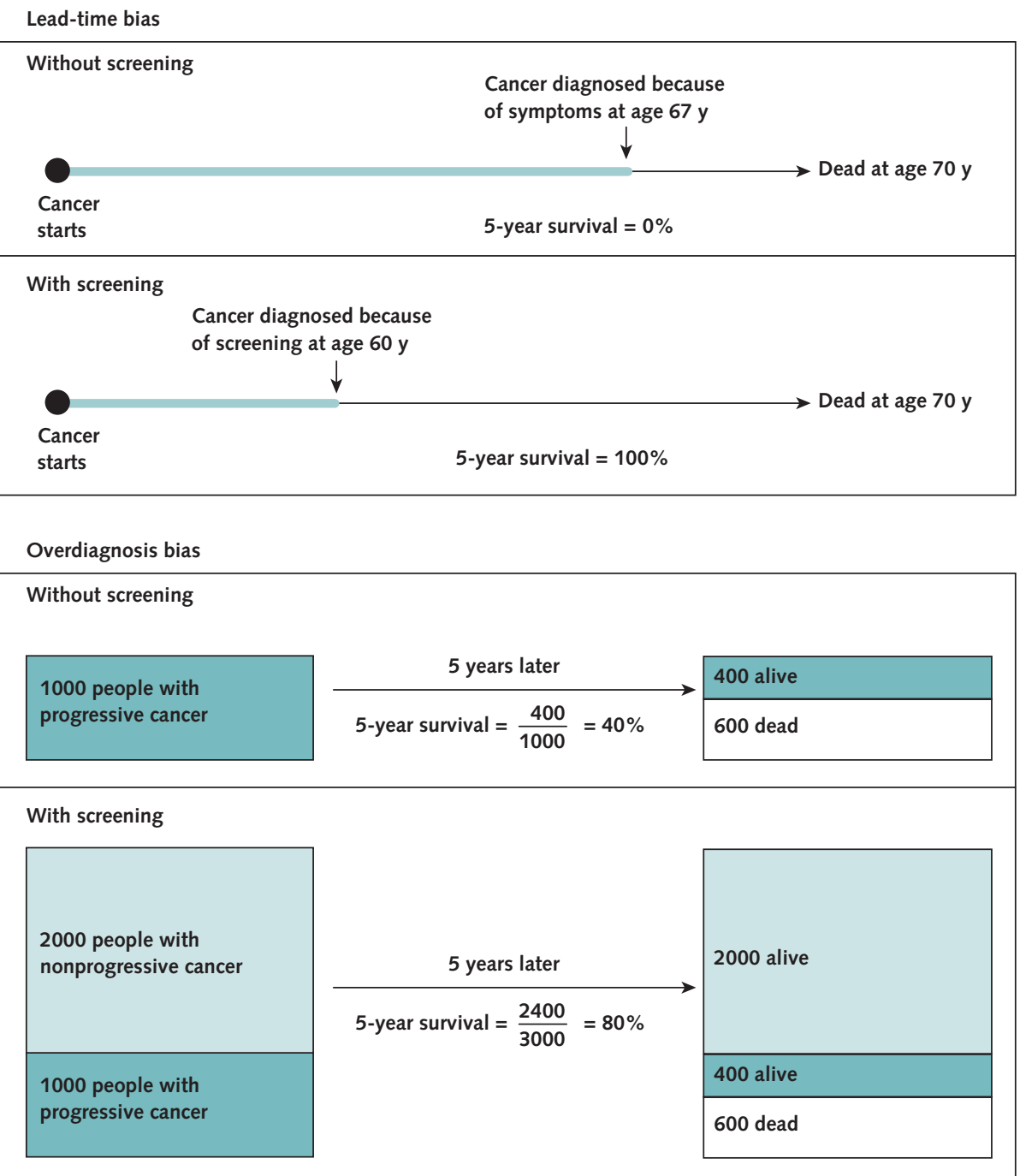

In lead-time bias, survival rates are inflated by earlier diagnosis even if mortality remains; in overdiagnosis bias, survival rates are inflated by the detection of nonprogressive cancer even if mortality remains unaltered. Figure reproduced from reference 2 with permission of the American Medical Association.

in wave 1 in 2010 and 115 in wave 2 in 2011), yielding a cooperation rate of $79 \%(412 /[412+110$ nonrespondents] $]$.

\section{Survey Questionnaire}

The online survey was revised after feedback from 5 physicians ( 1 in family medicine, 3 in internal medicine, and 1 in general medicine) who completed a pilot test. The final version of the survey is included in the Supplement (available at www.annals.org).

The survey introduced 2 hypothetical screening tests that were created by using data on prostate cancer. Fiveyear survival and percentage of stage I disease for prostate cancer were taken from the U.S. Surveillance, Epidemiology and End Results Program (9); we used data from 1975 for survival without screening because this year predates any organized screening efforts and from 2006 for survival with screening because that year more than one half of U.S. men aged 40 years or older reported having undergone prostate-specific antigen screening in the past 2 years (10). Cancer mortality and incidence with and without screening were obtained from the European Randomized Study of Screening for Prostate Cancer on prostate cancer screening (11). We used these data because they showed a mortality benefit, which we required for the scenario.

We did not tell physicians that the scenarios were based on data on prostate cancer screening and masked this by labeling the type of cancer and the screening tests in the scenarios "X" and "Z," respectively. First, physicians may have held strong beliefs about the effects of prostate cancer screening, which might have biased their responses. Second, we wished to avoid misinforming them about the 


\section{Figure 2. Study flow diagram.}

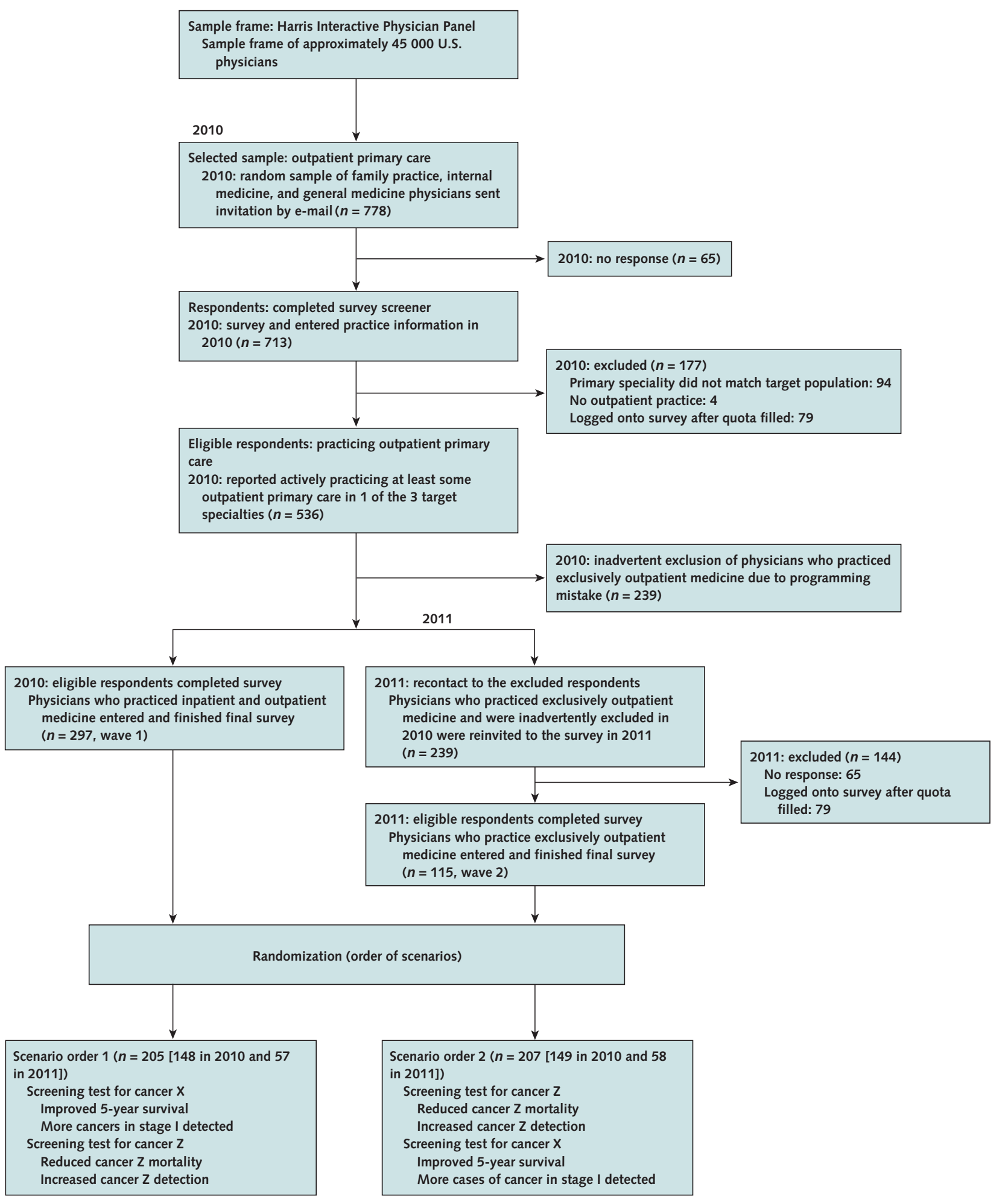


Table 1. Demographic Characteristics of the Sample

\begin{tabular}{|lc|}
\hline Characteristic & Participants, $\boldsymbol{n}(\%)^{*}$ \\
\hline Total & $412(100)$ \\
\hline $\begin{array}{l}\text { Practice type } \\
\text { Internal medicine }\end{array}$ \\
\hline Family practice & $135(33)$ \\
General practice & $253(61)$ \\
\hline Clinical timet & $24(6)$ \\
Exclusively outpatient & \\
\hline Mostly outpatient & $115(28)$ \\
\hline Mostly inpatient & $286(69)$ \\
\hline $\begin{array}{l}\text { Years in practice } \\
<10\end{array}$ & $11(3)$ \\
\hline $10-19$ & \\
\hline $20-29$ & $77(19)$ \\
\hline 30 & $174(42)$ \\
\hline Female & $125(30)$ \\
\hline Age & $36(9)$ \\
\hline $0-39$ y & $95(23)$ \\
\hline $50-49$ y & \\
\hline 60 y & $78(19)$ \\
\hline
\end{tabular}

* Percentages have been rounded and may not total 100\%.

† Of the 412 physicians, 297 "mostly outpatient" and "mostly inpatient" physicians were surveyed in a first wave in 2010. The 115 "exclusively outpatient" physicians who were inadvertently excluded in the first wave were recontacted and surveyed in a second wave in 2011.

evidence for screening in the course of this survey since other studies-most notably the American Prostate, Lung, Colorectal, and Ovarian Cancer Screening Trial on prostate cancer screening (12), which was published at the same time as the European study-did not show a reduction in prostate cancer mortality due to screening. Because the statistics on mortality and incidence in the European study were based on a median follow-up of 9 years, we adjusted these figures to a 5-year time frame to make them comparable to the 5-year survival rate.

Physicians were told that the tests described in the scenarios were noninvasive and free and detected cases of cancer for which treatment, such as surgery, exists. The effect of one test was described in terms of 5-year survival, and the effect of the other in terms of cancer mortality. These and the following effects were always described by providing numbers for the situation "with screening test" and "without screening test."

After responding to a series of questions about each of these tests, physicians were provided with additional information. Cancer mortality was followed by incidence, and 5 -year survival was followed by the proportion of cancer cases detected at stage I. This information was included because increased detection of cancer (that is, incidence)particularly at earlier stages-is sometimes mistakenly interpreted as proof that screening works.

We also tested the effect of 2 explanatory notes: one explaining that mortality in a randomized trial is the only reliable way to judge how well screening works, and the other explaining that increased incidence may represent overdiagnosis. The Supplement provides the exact language of the information provided and questions asked.

The study was primarily designed to assess physicians' understanding of common screening statistics. However, physicians might have responded differently to our questions depending on which statistic they saw first. To rule out an order effect, we randomly assigned one half of the sample to start with the survival statistic scenario and the other half to start with the mortality statistic scenario. Because order had no effect, we present combined data for the whole sample.

\section{Statistical Analysis}

Because the online version of the questionnaire did not allow item nonresponse, all 412 questionnaires were completed fully. To analyze within-physician outcomes (for example, recommendation of screening and judgment of the effectiveness of screening), we used the McNemar chi-square test and the Wilcoxon signed-rank test. Between-group analyses (for example, testing for order effects) were performed by using the Pearson chi-square test and the Mann-Whitney U test. All data were stored and analyzed by using SPSS 18 (SPSS, Chicago, Illinois).

Considering that the Harris Interactive Physician Panel does not precisely match the American Medical Association Masterfile on physician characteristics (such as years in practice) for our 3 target specialties, and to account for nonresponse of physicians invited to participate in the study, we created poststratification weights. These weights adjust the distributions of physician characteristics in our sample to match those in the American Medical Association Masterfile. The weighted and unweighted analyses yielded very similar results; here, we report the weighted results because they generate appropriate variance estimates and better reflect the general population of primary care physicians.

\section{Role of the Funding Source}

The study was funded both by the Harding Center for Risk Literacy at the Max Planck Institute for Human Development and by the National Cancer Institute. Neither funding source had a role in the design, conduct, collection, analysis, or interpretation of the data or in the preparation, review, or approval of the manuscript.

\section{RESULTS}

The responses of the 115 physicians surveyed in 2011 who practiced exclusively outpatient medicine and those of the 297 physicians surveyed in 2010 who practiced both inpatient and outpatient medicine were almost identical (Appendix Table, available at www.annals.org). All results are therefore reported in aggregate form. Table 1 shows the demographic characteristics of the sample. 


\section{Knowledge of What Counts as Relevant Evidence}

Primary care physicians demonstrated limited knowledge of what evidence might prove that a cancer screening test saves lives. About one half (47\%) incorrectly said that finding more cancer cases in screened as opposed to unscreened populations provided such proof (Figure 3). Many physicians did not distinguish between irrelevant evidence for screening (improved survival) and relevant evidence (reduced cancer mortality): Nearly as many physicians believed that survival data prove that screening saves lives $(76 \%)$ as believed that mortality data provide this proof $(81 \%)(P=0.39)$.

\section{Effect of Survival Versus Mortality Data on Physicians' Recommendations and Judgments of Benefit}

The same misconceptions were evident in physicians' responses about the potential benefits of the 2 hypothetical screening tests. Eighty percent of physicians said that the screening test supported by irrelevant evidence (5-year survival increased from $68 \%$ to $99 \%$ ) "saves lives from cancer," whereas only $60 \%$ said this about the test supported by relevant evidence (cancer mortality reduced from 2 to 1.6 in 1000 persons) $(P<0.001)$ (Table 2). Physicians were also 3 times more likely to say they would "definitely recommend" the test that improved 5-year survival com- pared with the one that reduced cancer mortality (69\% vs. 23\%; $P<0.001$ ) (Figure 4).

\section{Effect of Detecting More Early-Stage Cancer}

After seeing the data on the test that improved 5-year survival, physicians were then shown how the screening test increased the proportion of cases of cancer detected at stage I (from 36\% without screening to 54\% with screening). This information provides little support for a screening test because even a harmful test-one that increased mortality-could increase detection of early-stage cancer. Nonetheless, $68 \%$ of physicians said this information made them "more" or "much more" likely to recommend the test. In addition, $57 \%$ now expected the screening to save more lives from cancer than they had initially estimated without this additional information.

\section{Effect of Incidence Data}

After seeing the data on the test that reduced mortality, physicians were shown how the screening test increased cancer incidence (from 27 to 46 per 1000 persons over 5 years). Sixty-two percent of physicians said the increased incidence made them "more" or "much more" likely to recommend the test. In fact, 50\% now expected the screening to save even more lives from cancer even though the increased incidence is irrelevant to mortality. Overall, $11 \%$

\section{Figure 3. Physicians' understanding of which screening statistics provide evidence that screening saves lives.}

Which proves that a cancer screening test "saves lives"?

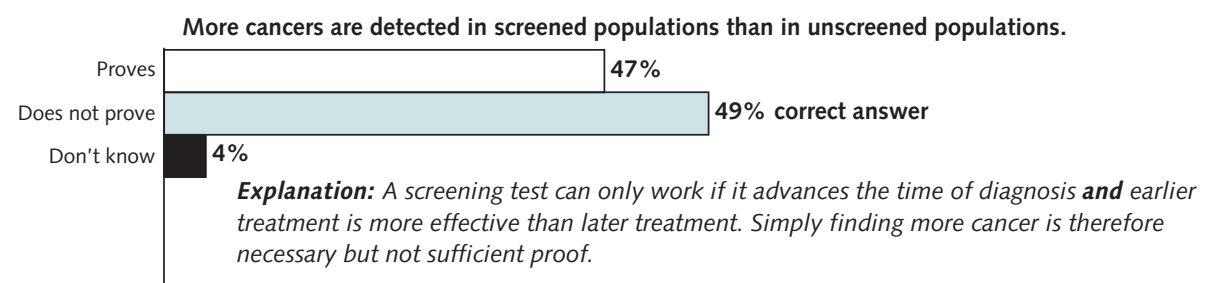

Screen-detected cancers have better 5-year survival rates than cancers detected because

of symptoms.

of diagnosis because of lead time. This is true whether or not the screening test saves lives.




ORIginal ReSEARCH Do Physicians Understand Cancer Screening Statistics?

Table 2. Physician Responses to Questions on the Effect of 2 Cancer Screening Tests, Using 2 Different Statistics

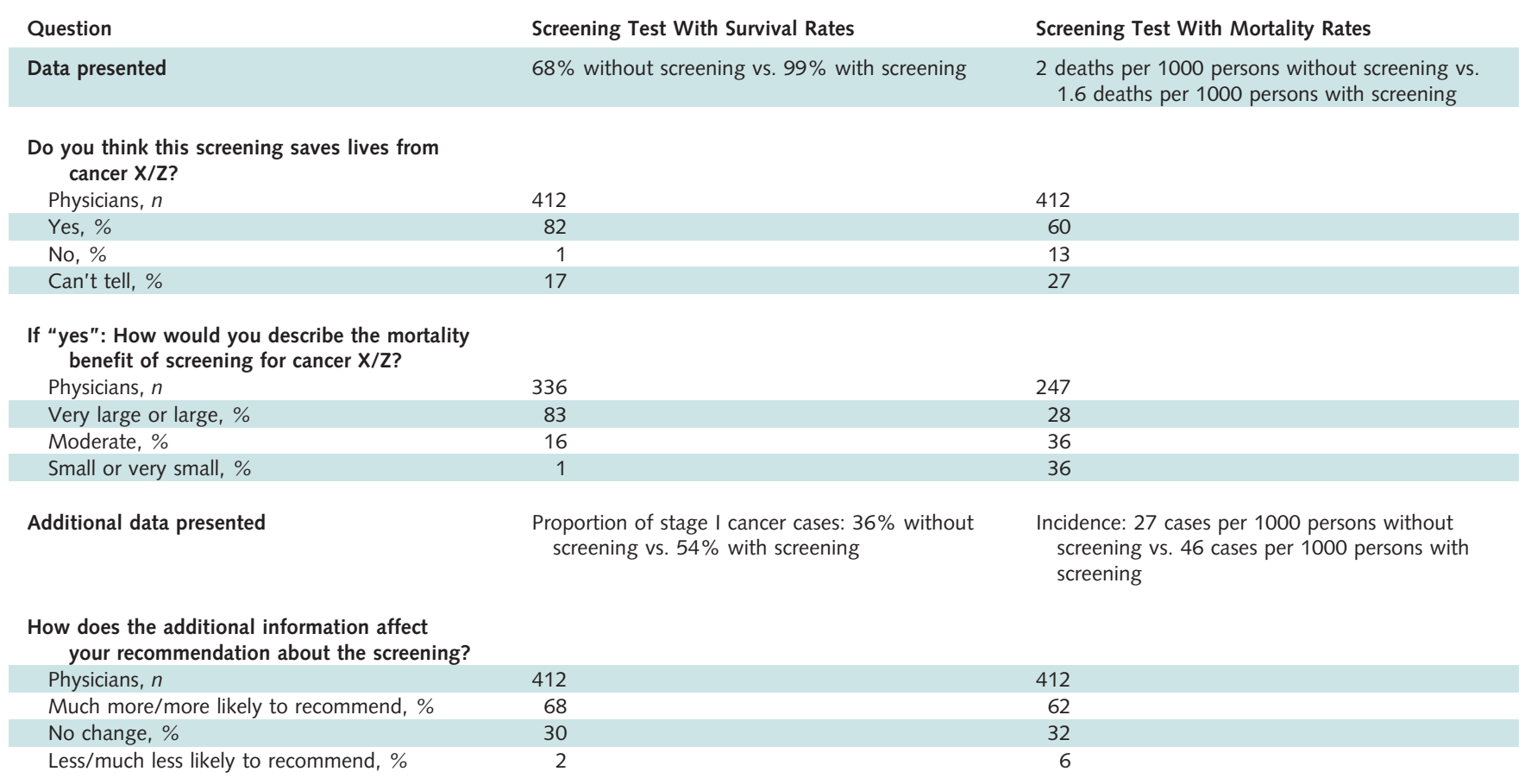

incorrectly endorsed the explanation that the "screened group must have had more cancer risk factors." Forty-two percent incorrectly believed that the "decreased mortality is all the more impressive given the higher incidence" with screening. More than one half (58\%) did not endorse the statement that "For every death prevented by screening, some people are diagnosed and treated with cancer $\mathrm{Z}$ unnecessarily," the most plausible explanation for the increased incidence.

\section{Effect of a Short Explanatory Note}

At the end of the scenario about the test that improved survival, physicians were presented with an explanatory note explaining that higher survival (or finding more cases of stage I cancer) with screening does not prove that screening saves lives and that such proof can come only from a randomized trial demonstrating lower cancer mortality. Although $76 \%$ of physicians stated that they found the note helpful, it had an inconsistent effect; $29 \%$ said it made them more likely to recommend the screening test, and $21 \%$ said it made them less likely.

At the end of the scenario about the test that reduced cancer mortality and increased incidence, physicians were presented with an explanatory note that highlighted the possibility of overdiagnosis (that is, to prevent 1 death from cancer Z, as many as 47 additional people would be diagnosed unnecessarily). Eighty percent found this note helpful, and $40 \%$ said that it made them less likely to recommend the test. However, 23\% said that it made them more likely to recommend the test.

\section{DISCUSSION}

The majority of primary care physicians did not know which screening statistics provide reliable evidence on whether screening works. They were more likely to recommend a screening test supported by irrelevant evidenceincreased 5-year survival with screening-than one supported by the relevant evidence-reduction in cancer mortality with screening.

The observed confusion is understandable. It is natural to assume that survival is the same as " 1 - mortality." That is what the words imply in common language and what the statistics imply in settings other than screening. For example, in a randomized trial of a treatment, survival is based on the starting trial population: If $10 \%$ of the patients die within 1 year, 90\% have survived. However, in the context of screening, the term "survival" takes on a different meaning because the calculation of survival has different starting points for screened and unscreened people.

We believe that many of the physicians mistakenly interpreted survival in screening as if it were survival in the context of a treatment trial. After seeing only the survival rates, nearly one half of the physicians who thought "lives were saved" said, in a fill-in-the-blank question, that there would be 300 to 310 fewer cancer deaths per 1000 people screened - a result apparently obtained by subtracting the 5 -year survival rates provided in the scenario ( $99 \%$ survival with screening minus $68 \%$ without screening $=31 \%$ ). However, the real reduction in cancer mortality found in 
the European Randomized Study of Screening for Prostate Cancer (10) is about 0.4 in 1000 within 5 years-an estimate that more than $50 \%$ of physicians provided when presented with cancer mortality rates (we accepted as correct any estimate between 0.4 and 1.0).

The magnitude of the mortality and survival numbers compounds the confusion. Because population mortality is low in the setting of screening, even an effective screening test can result in only a small absolute reduction in deaths from cancer (typically $1 \%$ or lower). With the exception of the most aggressive types of cancer, 5-year survival numbers for cancer are higher than mortality numbers. In addition, survival rates can increase dramatically with early detection alone because screening finds more cases of early cancer, for which survival is typically much higher. Not surprisingly, large survival changes in our scenario (from $68 \%$ to $99 \%$ ) appeared much more impressive than the numerically smaller mortality changes (2 to 1.6 in 1000 persons); $83 \%$ of physicians described the benefit of the screening test supported by survival rates as "large" or "very large," compared with only $28 \%$ for the test supported by mortality rates (Table 2 ).

Enthusiasm for screening was further increased by 2 other statistics: the percentage of stage I disease detected and cancer incidence. However, these statistics do not provide any information about a mortality benefit. It is particularly difficult to understand why incidence data would affect physicians' judgments about how well screening works when it was provided after the mortality rates. If anything, the ratio of 47 additional cancer diagnoses per life saved (that is, incidence increased from 27 to 46 per 1000 persons and mortality decreased from 2 to 1.6 per 1000 persons; 19 additional cancer diagnoses $/ 0.4$ fewer deaths $=$ $47)$ should suggest harm from overdiagnosis. Nonetheless, many physicians endorsed explanations about incidence that indicated that they had not considered the possibility of overdiagnosis.

Our study has limitations. First, physicians' recommendations for screening were based on hypothetical scenarios, not actual practice. It would be nearly impossible, however, to test the effect of a single statistic in any true clinical situation, where physicians' recommendations for screening are clearly determined by many factors besides their perceptions of benefits (for example, national guidelines, patient expectations, and fear of a malpractice lawsuit over missing a case of cancer $[13,14])$. Misunderstanding of statistics (Figure 3) nevertheless matters, because it may

Figure 4. Proportion of physicians who would recommend a screening test on the basis of survival versus mortality rates.

Would you recommend this screening test to your patient?

\begin{tabular}{lll} 
Data presented & \multicolumn{2}{c}{ Case 1: mortality data } \\
\cline { 2 - 3 } Correct answer & $\begin{array}{l}\text { No screening } \\
2 \text { deaths per 1000 }\end{array}$ & \multicolumn{1}{c}{ Screening } \\
& $\begin{array}{l}\text { Recommend screening because } \\
\text { reduced mortality is valid evidence of } \\
\text { benefit. }\end{array}$
\end{tabular}

\begin{tabular}{cc}
\multicolumn{2}{c}{ Case 2: 5 -year survival data } \\
\hline No screening & Screening \\
$68 \%$ & $99 \%$
\end{tabular}

Would not recommend screening because improved survival with screening is not valid evidence of benefit.

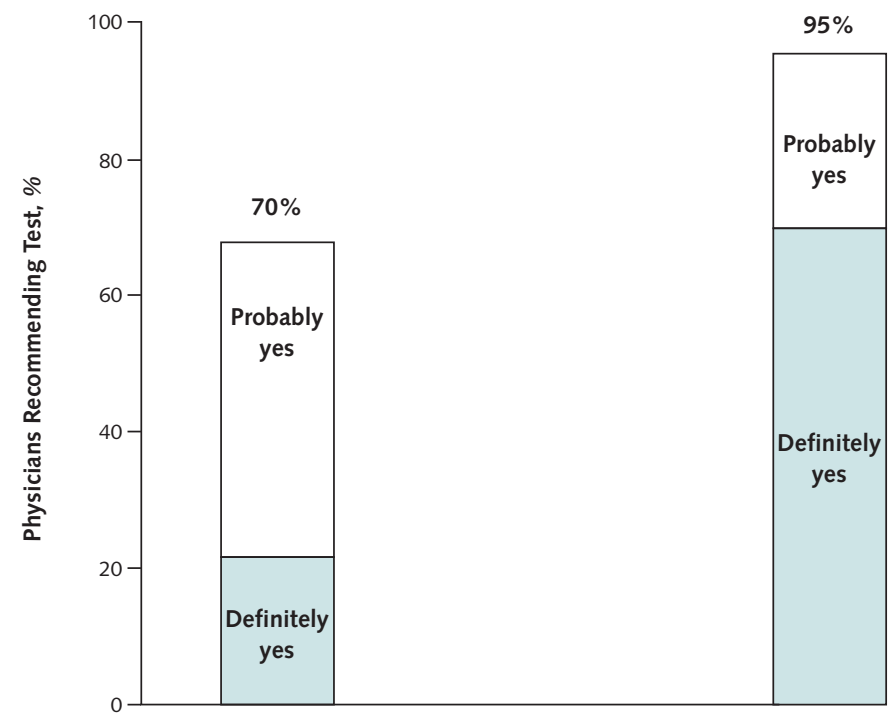


ORIginal ReSEARCH Do Physicians Understand Cancer Screening Statistics?

influence how physicians discuss screening with their patients or how they teach trainees.

Second, the adequacy of our correction for the initial mistaken exclusion of the 239 primary care physicians practicing exclusively outpatient medicine may raise some concern. We were able to recontact these physicians and accrue an additional 115 participants (the largest number possible within budget constraints). With these additional participants, we approximated the distribution of exclusively outpatient primary care physicians in the original study sample (39\% for the 2010 sample vs. $28 \%$ in the final sample). Most important, the responses of exclusively outpatient physicians were nearly identical to those of the other physicians.

Finally, we did not include information on harms within our hypothetical scenarios. We therefore do not know how such information may have altered physicians' recommendations of a screening test or their judgments of its benefit. Cancer screening can lead to harms, such as false-positive results, overdiagnosis, and overtreatment. Future research on how information about harms affects physicians' decision making will thus be useful.

Despite these limitations, our findings suggest that many physicians may be confused about cancer screening statistics. This matters because screening is an increasingly central part of medical practice. Physicians need to understand the key cancer statistics in order to answer patients' questions about the effectiveness of cancer screening correctly and assist them in making an informed decision (15). Studies have found that physicians are susceptible to framing effects created by using relative as opposed to absolute risk reduction formats $(16-19)$ and have difficulty calculating the positive predictive value (20-24). Our study demonstrates that many U.S. physicians also have trouble understanding screening statistics-a finding consistent with that of a small earlier pilot study conducted in a convenience sample of German physicians (25).

It is easy to be misled by statistics, particularly in the context of screening, where a familiar word like "survival" takes on an unfamiliar meaning. However, to better understand the true contribution of specific tests, physicians need to be made aware that in the context of screening, survival and early detection rates are biased metrics and that only decreased mortality in a randomized trial is proof that screening has a benefit.

From Harding Center for Risk Literacy, Max Planck Institute for Human Development, Berlin, Germany; the Dartmouth Institute for Health Policy and Clinical Practice, Dartmouth Medical School, Dartmouth, New Hampshire; and the Veterans Affairs Outcomes Group, White River Junction, Vermont.

Grant Support: The Harding Center for Risk Literacy, Max Planck Institute for Human Development, funded the study and provides support for Drs. Wegwarth, Gaissmaier, and Gigerenzer. Drs. Schwartz and Woloshin were supported by the National Cancer Institute (grant R01 CA104721).
Potential Conflicts of Interest: Disclosures can be viewed at www .acponline.org/authors/icmje/ConflictOfInterestForms.do?msNum=M11 $-1964$.

Reproducible Research Statement: Study protocol and data set: Not available. Statistical code: Available from Dr. Wegwarth (e-mail, wegwarth $@$ mpib-berlin.mpg.de).

Requests for Single Reprints: Odette Wegwarth, PhD, Max Planck Institute for Human Development, Lentzeallee 94, 14195 Berlin, Germany; e-mail,wegwarth@mpib-berlin.mpg.de.

Current author addresses and author contributions are available at www annals.org.

\section{References}

1. Welch HG, Schwartz LM, Woloshin S. Are increasing 5-year survival rates evidence of success against cancer? JAMA. 2000;283:2975-8. PMID: 10865276] 2. Welch HG, Woloshin S, Schwartz LM, Gordis L, Gøtzsche PC, Harris R, et al. Overstating the evidence for lung cancer screening: the International Early Lung Cancer Action Program (I-ELCAP) Study. Arch Intern Med. 2007;167: 2289-95. [PMID: 18039986]

3. Folkman J, Kalluri R. Cancer without disease. Nature. 2004;427:787. [PMID: 14985739]

4. Mooi WJ, Peeper DS. Oncogene-induced cell senescence-halting on the road to cancer. N Engl J Med. 2006;355:1037-46. [PMID: 16957149]

5. Serrano M. Cancer regression by senescence. N Engl J Med. 2007;356: 1996-7. [PMID: 17494935]

6. Welch HG, Black WC. Overdiagnosis in cancer. J Natl Cancer Inst. 2010; 102:605-13. [PMID: 20413742]

7. Measurement of progress against cancer. Extramural Committee to Assess Measures of Progress Against Cancer. J Natl Cancer Inst. 1990;82:825-35. [PMID: 2332901]

8. Harris Interactive Physician Panel. Accessed at www.harrisinteractive.com /MethodsTools/DataCollection/SpecialtyPanelsPanelDevelopment/PhysiciansPanel .aspx on 18 October 2010.

9. SEER Cancer Statistics Review. Accessed at http://seer.cancer.gov/csr /1975_2008/index.html on January 2009.

10. Centers for Disease Control and Prevention, Office of Surveillance, Epidemiology, and Laboratory Services, Behavioral Risk Factor Surveillance System. Prevalence and Trends Data: Nationwide (States, DC, and Territories) - 2006. Prostate Cancer. Accessed at http://apps.nccd.cdc.gov/BRFSS/display.asp?cat $=\mathrm{PC} \& \mathrm{yr}=2006 \& \mathrm{qkey}=4423 \&$ state $=$ US on November 2011.

11. Schröder FH, Hugosson J, Roobol MJ, Tammela TL, Ciatto S, Nelen V, et al; ERSPC Investigators. Screening and prostate-cancer mortality in a randomized European study. N Engl J Med. 2009;360:1320-8. [PMID: 19297566] 12. Andriole GL, Crawford ED, Grubb RL 3rd, Buys SS, Chia D, Church TR, et al; PLCO Project Team. Mortality results from a randomized prostate-cancer screening trial. N Engl J Med. 2009;360:1310-9. [PMID: 19297565]

13. Studdert DM, Michelle M, Sage WM, DesRoches CM, Peugh J, Zapert K, et al. Defensive medicine among high-risk specialist physicians in a volatile malpractice environment. JAMA. 2005;293:2609-17. [PMID: 15928282]

14. Studdert DM, Mello MM, Gawande AA, Gandhi TK, Kachalia A, Yoon C, et al. Claims, errors, and compensation payments in medical malpractice litigation. N Engl J Med. 2006;354:2024-33. [PMID: 16687715]

15. Rimer BK, Briss PA, Zeller PK, Chan EC, Woolf SH. Informed decision making: what is its role in cancer screening? Cancer. 2004;101(5 Suppl):1214-28. [PMID: 15316908]

16. McGettigan P, Sly K, O'Connell D, Hill S, Henry D. The effects of information framing on the practices of physicians. J Gen Intern Med. 1999;14: 633-42. [PMID: 10571710]

17. Jain BP. Number needed to treat and relative risk reduction. Ann Intern Med. 1998;128:72-3. [PMID: 9424990]

18. Naylor CD, Chen, E, Strauss B. Measured enthusiasm: does the method of reporting trial results alter perceptions of therapeutic effectiveness? Ann Intern Med. 1992;117:916-21. [PMID: 1443954]

19. Covey J. A meta-analysis of the effects of presenting treatment benefits in 
different formats. Med Decis Making. 2007;27:638-54. [PMID: 17873250]

20. Eddy DM. Probabilistic reasoning in clinical medicine: problems and opportunities. In: Kahneman D, Slovic P, Tversky A, eds. Judgment under Uncertainty: Heuristics and Biases. Cambridge, UK: Cambridge Univ Pr; 1982: 249-67.

21. Casscells W, Schoenberger A, Graboys TB. Interpretation by physicians of clinical laboratory results. N Engl J Med. 1978;299:999-1001. [PMID: 692627]

22. Bramwell R, West H, Salmon P. Health professionals' and service users' interpretation of screening test results: experimental study. BMJ. 2006;333:284.
[PMID: 16840441]

23. Hoffrage U, Gigerenzer G. Using natural frequencies to improve diagnostic inferences. Acad Med. 1998;73:538-40. [PMID: 9609869]

24. Wegwarth O, Gigerenzer G. "There is nothing to worry about": gynecologists' counseling on mammography. Patient Educ Couns. 2011;84:251-6. [PMID: 20719463]

25. Wegwarth O, Gaissmaier W, Gigerenzer G. Deceiving numbers: survival rates and their impact on doctors' risk communication. Med Decis Making. 2011;31:386-94. [PMID: 21191123] 


\section{Annals of Internal Medicine}

Current Author Addresses: Drs. Wegwarth, Gaissmaier, and Gigerenzer: Max Planck Institute for Human Development, Harding Center for Risk Literacy, Lentzeallee 94, 14195 Berlin, Germany.

Drs. Schwartz and Woloshin: Dartmouth Institute for Health Policy and Clinical Practice, 35 Centerra Parkway, Lebanon, NH 03766.

Author Contributions: Conception and design: O. Wegwarth, L.M. Schwartz, S. Woloshin, G. Gigerenzer.

Analysis and interpretation of the data: O. Wegwarth, L.M. Schwartz, S. Woloshin, W. Gaissmaier, G. Gigerenzer.

Drafting of the article: O. Wegwarth, L.M. Schwartz, S. Woloshin.
Critical revision of the article for important intellectual content: $\mathrm{O}$. Wegwarth, L.M. Schwartz, S. Woloshin, G. Gigerenzer.

Final approval of the article: O. Wegwarth, L.M. Schwartz, S. Woloshin, W. Gaissmaier, G. Gigerenzer.

Provision of study materials or patients: O. Wegwarth.

Statistical expertise: O. Wegwarth, L.M. Schwartz, S. Woloshin, W. Gaissmaier, G. Gigerenzer.

Obtaining of funding: G. Gigerenzer.

Administrative, technical, or logistic support: O. Wegwarth, G. Gigerenzer.

Collection and assembly of data: O. Wegwarth. 


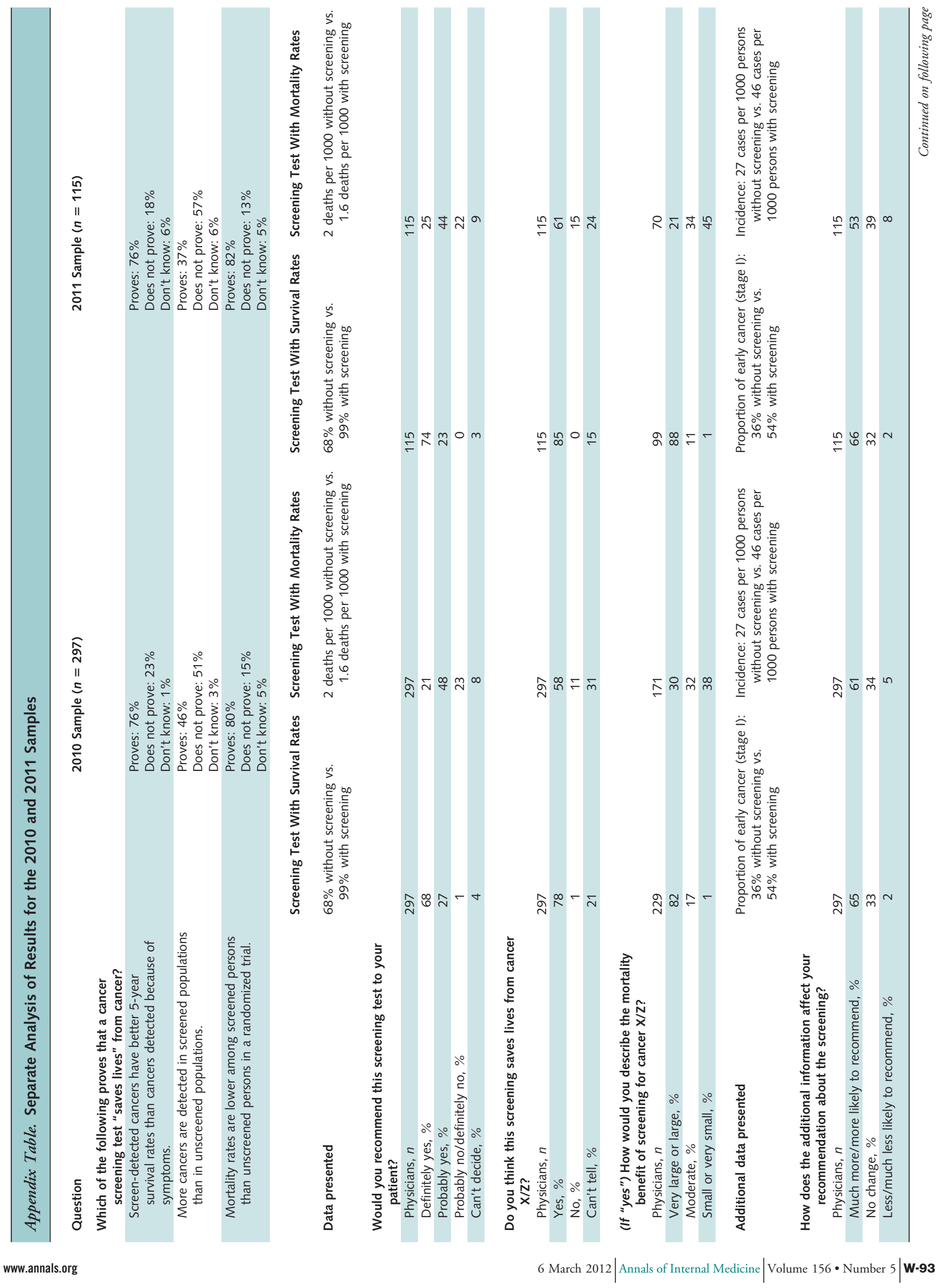




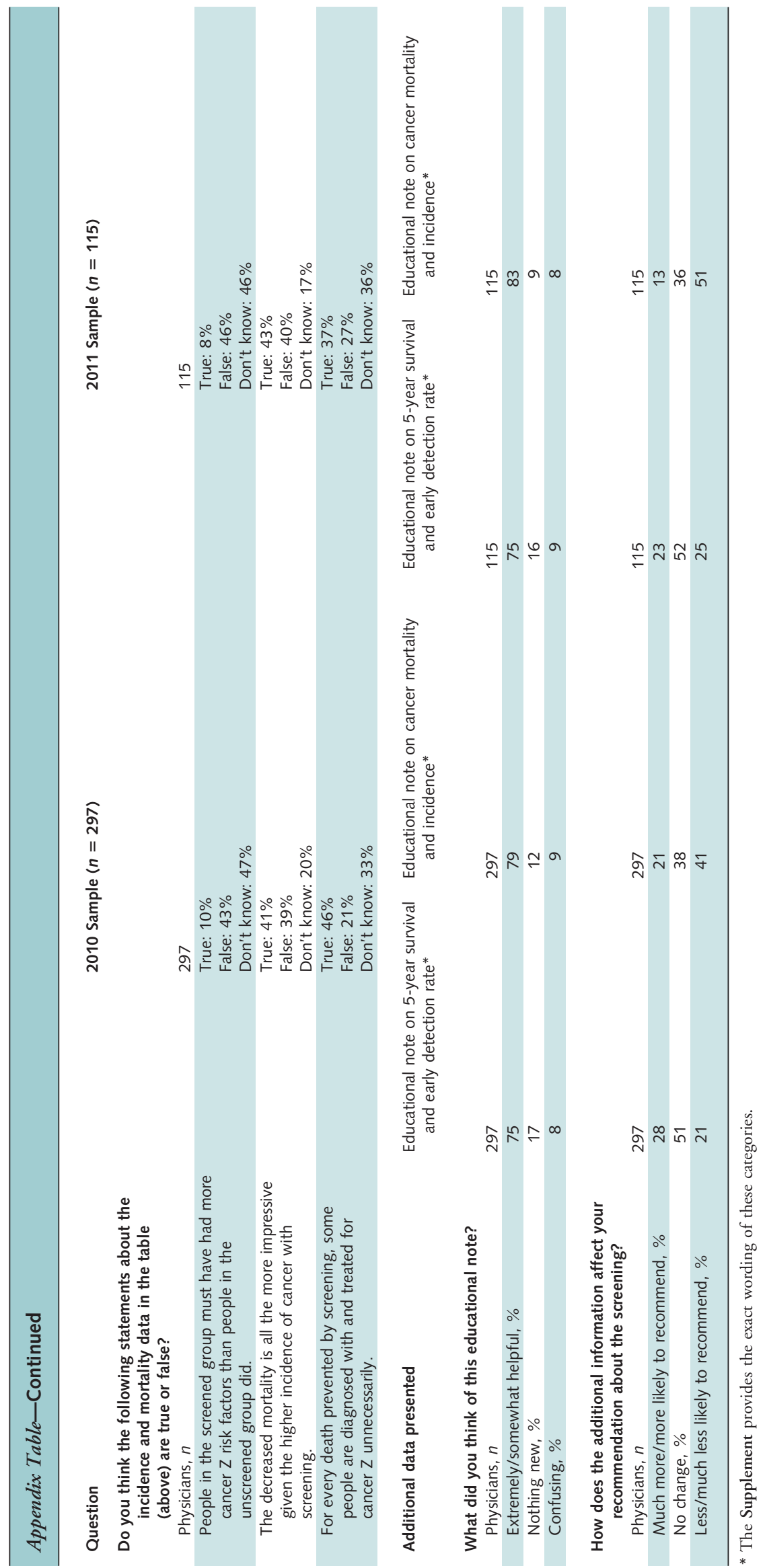

W-94 6 March 2012 Annals of Internal Medicine $\mid$ Volume 156 • Number 5 
Copyright (C) American College of Physicians 2012. 